\title{
PENGARUH PERSONALITY TRAITS DAN ETHICAL LEADERSHIP TERHADAP JOB SATISFACTION PEGAWAI BCA KALIMALANG
}

\author{
Jimmy Lukito dan Edalmen \\ Program Studi S1 Manajemen Fakultas Ekonomi Universitas Tarumanagara, Jakarta \\ <jimmy.115160183@stu.untar.ac.id>
}

\begin{abstract}
This study was conducted with the aim of finding out whether there is an effect of personality traits and ethical leadership on job satisfaction among employees of PT Bank Central Asia's Kalimalang branch, East Jakarta. The subjects of this study were 50 employees of PT Bank Central Asia's Kalimalang branch. The sampling method is done by purposive sampling method. This study uses data analysis with the Partial Least Square (PLS) approach in the form of the Smart-PLS application version 3.0. The findings show that personality traits significantly and positively affect job satisfaction. Also, there is a significant and positive effect of ethical leadership on job satisfaction.
\end{abstract}

Keywords: Personality Traits, Ethical Leadership, Job Satisfaction.

Abstrak: Penelitian ini dilakukan dengan tujuan untuk mengetahui apakah terdapat pengaruh personality traits dan ethical leadership terhadap job satisfaction pada pegawai PT Bank Central Asia cabang Kalimalang, Jakarta Timur. Subyek penelitian ini adalah 50 pegawai PT Bank Central Asia cabang Kalimalang, Jakarta Timur. Metode pengambilan sampel dilakukan dengan metode purposive sampling. Penelitian ini menggunakan analisis data dengan pendekatan Partial Least Square (PLS) berupa aplikasi SmartPLS versi 3.0. Temuan menunjukkan bahwa terdapat pengaruh yang positif dan signifikan dari personality traits terhadap job satisfaction. Selain itu, ethical leadership juga turut mempengaruhi secara positif dan signifikan terhadap job satisfaction.

Kata Kunci: Ciri-ciri Kepribadian, Kepemimpinan Etis, Kepuasan Kerja.

\section{LATAR BELAKANG}

Sumber daya manusia (SDM) memiliki peran penting sebagai penggerak seluruh aktivitas organisasi maupun aktivitas bisnis suatu perusahaan. Selain itu, SDM yang baik juga dapat meningkatkan kemampuan bersaing suatu perusahaan. Keberhasilan suatu organisasi (Vijayabanu dan Amudha, 2012) tergantung pada penggunaan tenaga kerja yang tepat yang akan menjadi pelengkap semua aset lainnya. Untuk itu setiap perusahaan harus bisa menjaga dan memelihara karyawan mereka. Salah satu cara untuk menjaga dan memelihara karyawan mereka adalah memperhatikan kepuasan kerja karyawan. Karyawan yang merasa puas dengan pekerjaannya akan menikmati pekerjaannya sehingga karyawan tersebut dapat mengerjakan perkerjaannya tanpa ada tekanan. 
Kepuasan karyawan memainkan peran penting dalam keberhasilan organisasi mana pun, dan tidak terkecuali bank. Agar bank muncul sebagai entitas finansial yang berdaya saing global, kepuasan karyawan perlu diperhatikan. Akan tetapi, tingkat kepuasan kerja di Indonesia masih sangat rendah. Berdasarkan studi yang dilakukan oleh Dale Carnegie pada tahun 2016 yang bertajuk "Global Leadership Study" menyatakan bahwa hanya 17\% pekerja di Indonesia yang mengaku puas akan pekerjaannya. Studi ini melibatkan sekitar 205 pekerja dengan rentang usia 22-61 tahun, mulai dari level karyawan hingga direktur dari perusahaan kecil hingga menengah. Lebih lanjut, hanya $28 \%$ pekerja yang memiliki keinginan untuk menetap di perusahaan tersebut dalam jangka waktu lama (intention to stay). Sementara itu, $13 \%$ pekerja ingin pindah dari tempat kerjanya dan $20 \%$ pekerja mengaku sudah berniat mencari pekerjaan saat itu.

Rendahnya tingkat kepuasan kerja di Indonesia perlu mendapatkan perhatian penting. Perusahaan perlu menciptakan iklim kerja yang nyaman demi mempertahankan kepuasan kerja karyawan mereka. Setiap SDM adalah individu yang berbeda dan beragam. Oleh karena itu faktor yang mempengaruhi tingkat kepuasan kerja juga beragam. Banyak sekali faktor yang mempengaruhi kepuasan kerja karyawan. Faktor-faktor tersebut saling berkaitan dan bersamasama mempengaruhi kepuasan kerja karyawan.

Salah satu faktor yang umum digunakan untuk meneliti kepuasan kerja (job satisfaction) adalah ciri-ciri kepribadian (personality traits). Konsep personality traits ini sudah ada sejak lama dimana konsep ini pertama kali dikemukakan oleh Norman (1963) dan dikenal dengan sebutan "Norman's Big Five" atau "Big Five Personality traits". Ciri-ciri kepribadian tersebut antara lain agreeableness, conscientiousness, extraversion, emotional stability dan culture. Namun, beberapa peneliti memiliki pandangan yang berbeda kepada ciri yang ke-5, dimana Norman (1963) menggunakan ciri culture, Borgatta (1964) menggunakan ciri intellect dan McCrae \& Costa (1985) menggunakan ciri openness to experience. Dalam penelitian ini, ciri ke-5 yang digunakan adalah ciri dari McCrae \& Costa (1985) yaitu openness to experience sehingga kelima ciri-ciri kepribadian yang digunakan dalam penelitian ini untuk meneliti hubungannya dengan kepuasan kerja adalah agreeableness, conscientiousness, extraversion, emotional stability, dan openess to experience. Kepribadian menentukan presepsi seseorang dalam menghadapi stress dan tekanan yang mungkin terjadi saat bekerja yang berhubungan dengan tingkat kepuasan mereka terhadap pekerjaan serta tempat kerja mereka saat ini. Penelitian ini akan meneliti ciri-ciri kepribadian manakah yang paling mempengaruhi kepuasan kerja merja pada pegawai PT Bank Central Asia di cabang Kalimalang, Jakarta Timur.

Sementara itu, kepemimpinan etis juga turut mempengaruhi kepuasan kerja. Kepemimpinan etis menumbuhkan kepuasan kerja individu dengan menciptakan iklim etis dalam organisasi (Avey et al., 2012). Karyawan di bawah pengawasan kepemimpinan etis dengan jelas memahami apa yang seharusnya dan tidak seharusnya mereka lakukan. Dengan demikian, karyawan memiliki pandangan yang jelas tentang kesesuaian dan ketidaksesuaian perilaku mereka sehingga dapat membantu menumbuhkan kepuasan kerja individu. Hal ini berlaku pula pada karyawan di Bank BCA. Karyawan di Bank BCA diajarkan dan dilatih dibawah supervisor mereka yang biasa berada di cabang mereka. Bahkan, terkadang supervisor mereka pun ikut membantu dalam proses pelayanan nasabah bank BCA. Karyawan yang melihat atasannya ikut membantu secara tidak langsung termotivasi karena melihat contoh perilaku yang seharusnya dilakukan dan secara tidak langsung menumbuhkan kepuasan kerja diantara karyawan BCA. 
Oleh karena itu, penelitian ini dilakukan dengan dua tujuan, yang pertama yaitu untuk meneliti apa pengaruh personality traits terhadap job satisfaction. Kedua, yaitu untuk meneliti pengaruh ethical leadership terhadap job satisfaction. Metode, hasil penelitian, diskusi, dan penelitian lebih lanjut akan dibahas pada bagian selanjutnya.

\section{KAJIAN TEORI}

Salah satu teori yang paling sering digunakan untuk menjelaskan kepribadian seseorang adalah Big Five Personality Traits (Big Five) atau yang sering dikenal juga sebagai teori FiveFactors Model (FFM). Teori ini menjelaskan bahwa setiap individu memiliki 5 traits kepribadian, namun hanya satu dimensi yang dominan. Teori Big Five merupakan salah satu teori kepribadian yang dapat memprediksi dan menjelaskan perilaku seseorang. Teori ini merupakan pendekatan yang digunakan oleh para psikologi untuk melihat kepribadian yang telah dibentuk dengan menggunakan analisis faktor (Feist \& Feist, 2009).

Kepribadian merupakan organisasi dinamis dalam individu sebagai sistem psikofisik individu yang menentukan perilaku khas dan pemikirannya (Allport, 1961; dalam Feist \& Feist, 2008). Menurut McCrae dan Costa (1997) personality traits terbagi menjadi 5 sifat dasar yang dominan. Sifat dasar tersebut antara lain agreeableness, conscientiousness, extraversion, emotional stability, dan opness to experience.

Seorang yang memiliki agreebleness yang tinggi digambarkan sebagai seorang yang memiliki value suka membantu, forgiving, penyayang, selalu mengalah, menghidari sebuah konflik, dan memiliki kecenderungan untuk mengikuti orang lain. Orang memiliki conscientiousness yang tinggi umumnya berhati-hati, dapat diandalkan, teratur, dan bertanggung jawab. Extraversion dicirikan sebagai individu yang percaya diri, dominan, aktif, dan menunjukan emosi yang positif serta dikaitkan juga dengan kecenderungan untuk bersikap optimis. Orang yang memiliki sisi emotional stability yang tinggi dicirikan dengan kepemilikan emosi yang positif seperti rasa tenang, dan rasa aman, serta serta lebih gembira dan puas terhadap hidup. Selain itu, Seseorang dengan tingkat openess to experience yang tinggi cenderung senang dengan informasi baru, bersedia melakukan penyesesuaian pada suatu ide atau situasi yang baru, mudah bertoleransi, memiliki kapasitas untuk menyerap informasi, fokus, kreatif, dan artistik (Ramadhani 2012: 9).

Sementara itu, ethical leadership mengacu pada proses memengaruhi karyawan melalui nilai-nilai, prinsip-prinsip dan keyakinan yang secara luas berbatasan dengan norma-norma yang diterima dalam perilaku organisasi (Bubble, 2012). Ethical leadership pertama kalinya dikemukakan oleh Greenleaf (1977) sebagai kepemimpinan yang pada hakikatnya terkait dengan pelayanan atau dikenal sebagai servant leadership. Pelayanan yang dimaksudkan disini yaitu pelayanan yang diberikan pimpinan kepada bawahannya yang menjadi tanggungjawab dari seorang pimpinan yang meliputi pengasuhan, mempertahankan, dan memberikan wewenang kepada bawahan. Dalam hal ini, pimpinan harus membantu karyawan agar menjadi lebih baik lagi, bijaksana, dan mampu bertanggungjawab dalam menjalankan segala aspek tugas dan fungsinya.

Kepuasan kerja atau job satisfaction mengacu pada suatu sikap umum seorang terhadap pekerjaannya (Stephen Robbins, 1996: 179). Pekerjaan mengharuskan adanya interaksi dengan rekan kerja, atasan, standar kinerja, peraturan dan kebijakan organisasi, kondisi kerja dan lain-lain. Seorang dengan tingkat kepuasan kerja tinggi akan menunjukkan sikap positif terhadap pekerjaan yang ia jalani atau lakukan, Sedangkan apabila seorang pekerja tidak puas dengan pekerjaanya ia akan menunjukkan sikap negatif terhadap pekerjaanya tersebut. 
Model penelitian ini dapat digambarkan sebagai berikut:

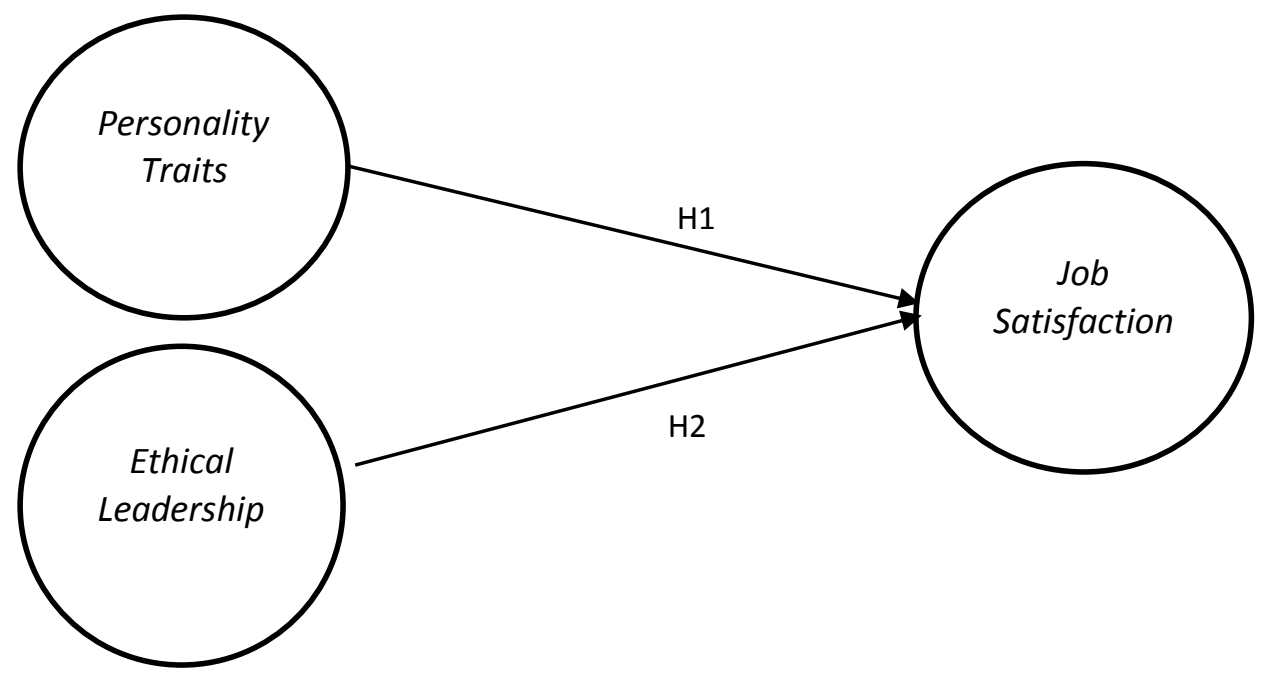

Gambar 1

Model Penelitian

Berdasarkan model penelitian di atas, hipotesis dari penelitian ini adalah sebagai berikut:

H1 : Personality traits memiliki pengaruh positif dan signifikan terhadap job satisfaction.

$\mathrm{H} 2$ : Ethical Leadership memiliki pengaruh positif dan signifikan terhadap job satisfaction.

\section{METODOLOGI}

Data diambil dari pegawai PT Bank Central Asia caban Kalimalang, Jakarta Timur yang berjumlah 50 orang. Teknik pemilihan teknik pemilihan sampel yang digunakan dalam penelitian ini adalah teknik teknik pengambilan sampel bertujuan (purposive sampling) dimana sampel harus bekerja di PT Bank Central Asia cabang Kalimalang, Jakarta Timur sebagai pertimbangan pemilihan sampel. Instrumen yang digunakan adalah kuisioner secara online menggunakan google form. Data diolah menggunakan metode Partial Least Square (PLS) dengan aplikasi Smart-PLS versi 3.0.

Penelitian ini menggunakan tiga variabel yaitu, variabel personality traits, ethical leadership, dan job satisfaction. Variabel personality traits memiliki 16 item yang diadaptasi dari Cheng-Liang \& Hwang (2014). Variabel ethical leadership memiliki 10 item yang diadaptasi oleh Ko et al. (2018). Variabel job satisfaction memiliki 6 item yang diadaptasi oleh Guchait et al. (2016). Semua konstuk diukur menggunakan skala Likert 5 poin. 
Analisis data dilakukan melalui uji outer model dan inner model. Berikut gambar hasil pengujian outer model yang menggunakan analisis PLS Algorithm:

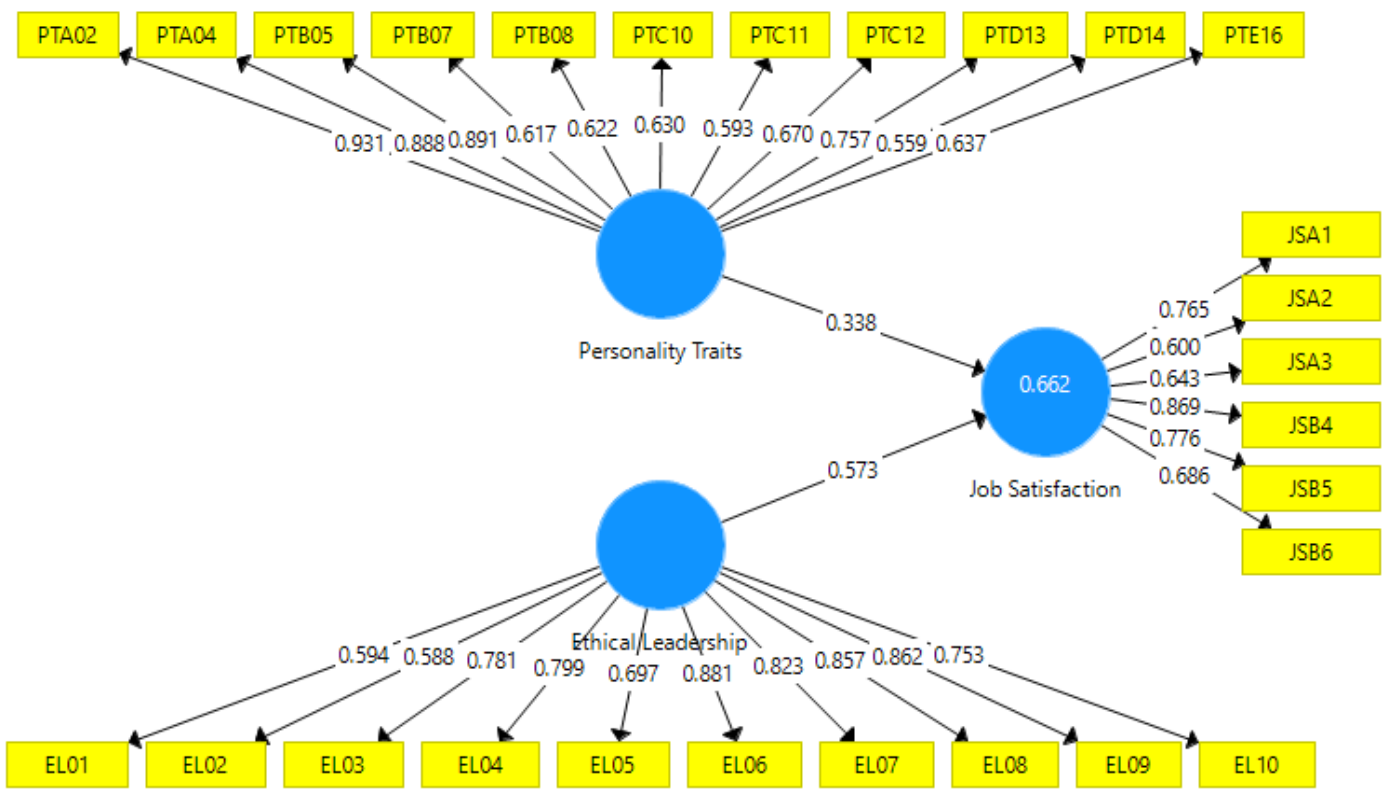

Gambar 2

\section{Hasil Analisis PLS Algorithm}

Hasil dari pengujian outer model terdapat angka loading factor yang harus dieliminasi karena tidak memenuhi syarat. Adapun indikator yang dieliminasi adalah PTA1, PTA3, PTB6, PTC9, PTE15.

\section{Tabel 1}

Tabel AVE

\begin{tabular}{|c|c|c|}
\hline Variabel & Nilai AVE & Keterangan \\
\hline Personality Traits & 0,519 & Valid \\
\hline Ethical Leadership & 0,593 & Valid \\
\hline Job Satisfaction & 0,531 & Valid \\
\hline
\end{tabular}

Uji validitas dilakukan dengan melihat nilai AVE. Apabila nilai AVE lebih besar atau sama dengan 0,5 (Hair et al., 2012) maka instrumen penelitian tersebut dapat dikatakan valid. Hasil pengujian menunjukkan bahwa semua item dalam penelitian ini memiliki nilai AVE lebih besar dari 0,5. Dengan demikian, semua item dalam penelitian ini adalah valid. 
Tabel 2

Tabel Cronbach's Alpha

\begin{tabular}{|c|c|c|}
\hline Variabel & Nilai Cronbach's Alpha & Keterangan \\
\hline Personality Traits & 0,902 & Reliabel \\
\hline Ethical Leadership & 0,922 & Reliabel \\
\hline Job Satisfaction & 0,819 & Reliabel \\
\hline
\end{tabular}

Uji reliabilitas instrumen dalam PLS menggunakan Cronbach's Alpha dari blok indikator yang mengukur konstruknya. Suatu instrumen dikatakan reliabel jika nilai Cronbach's Alpha berada di atas tingkat ambang 0,7 (Nunnally, 1967). Hasil Pengujian menunjukkan bahwa semua item dalam penelitian ini memiliki nilai Cronbach's Alpha lebih besar dari 0,7.

Tabel 3

Tabel $R$ Square

\begin{tabular}{|c|c|}
\hline & $\mathbf{R}^{\mathbf{2}}$ \\
\hline Job Satisfaction & 0,662 \\
\hline
\end{tabular}

Uji koefisien determinasi dilakukan dengan melihat nilai $R$ Square. Nilai $R$ square digunakan untuk menilai variasi pengaruh variabel independen terhadap variabel dependen. Hasil pengujian menunjukkan bahwa nilai $R$ Square untuk variabel job satisfaction adalah 0,662. Artinya, variabel job satisfaction dapat dijelaskan oleh variabel personality traits dan ethical leadership sebesar 66,2 persen sementara sisanya sebesar 33,8 persen dijelaskan oleh variabel lain yang tidak terdapat dalam penelitian ini.

Tabel 4

Tabel Uji Hipotesis

\begin{tabular}{|c|c|c|c|}
\hline Variabel & T-Statistik & P Values & Keterangan \\
\hline H1: Personality Traits $\rightarrow$ Job Satisfaction & 3,097 & 0,002 & Tidak Ditolak \\
\hline H2: Ethical Leadership $\rightarrow$ Job Satisfaction & 5,192 & 0,000 & Tidak Ditolak \\
\hline
\end{tabular}

Pengujian hipotesis dilakukan dengan menggunakan metode bootstrapping. Pengujian hipotesis dilakukan dengan membandingkan nilai $p$-value dengan tingkat kepercayaan $(\alpha)$ sebesar 0,05. Koefisien regresi adalah signifikan apabila nilai $p$-value < 0,05 (Haryono, 2017).

Hasil pengujian H1 untuk menguji pengaruh personality traits terhadap job satisfaction menunjukkan nilai $p$-value sebesar 0,002. Dengan demikian, dapat disimpulkan bahwa H1 tidak ditolak. 
Hasil pengujian $\mathrm{H} 2$ untuk menguji pengaruh ethical leadership terhadap job satisfaction menunjukkan nilai $p$-value sebesar 0,000. Dengan demikian, dapat disimpulkan bahwa $\mathrm{H} 2$ tidak ditolak.

\section{DISKUSI}

Penelitian ini menemukan bahwa personality traits berpengaruh positif dan signifikan terhadap job satisfaction. Dengan demikian, semakin dominan personality traits yang dimiliki seorang karyawan berbanding lurus dengan tingkat job satisfaction karyawan. Hasil penelitian ini sesuai dengan penelitian Chandrasekara (2019), Suo Honggang (2008), Tokar \& Subich (1997), dan Templer (2012).

Karyawan yang ramah dan mudah didekati lebih mungkin memenuhi kebutuhan sosial dari pekerjaan mereka, dengan demikian, mereka lebih cenderung menghasilkan kepuasan kerja. Karyawan yang memiliki conscientiousness yang tinggi akan lebih mendalami pekerjaannya sehingga memiliki peluang lebih besar untuk dihargai atas pekerjaan mereka, dan karenanya, memiliki kepuasan kerja yang lebih tinggi secara keseluruhan.

Selain itu, penelitian ini juga menemukan bahwa ethical leadership memiliki pengaruh positif dan signifikan terhadap job satisfaction. Artinya pemimpin yang menerapkan kepemimpinan etis akan berpengaruh secara positif terhadap kepuasan kerja karyawan. Hasil penelitian ini sesuai dengan penelitian yang dilakukan Avey et al. (2012), Tu et al. (2017), dan Qing et al. (2018).

Ketika pemimpin membuat keputusan penting terkait merancang pekerjaan, evaluasi kinerja, dan kegiatan promosi, para pemimpin etis memperlakukan karyawan secara adil. Perilaku dan atribut ini memicu kepercayaan dan antusiasme di antara karyawan. Hal ini akan menimbulkan rasa nyaman dalam lingkungan kerja si karyawan sehingga dapat meningkatkan kepuasan kerja.

\section{PENUTUP}

Berdasarkan hasil pengujian tersebut, maka dapat disimpulkan bahwa terdapat pengaruh positif personality traits terhadap job satisfaction. Selain itu, terdapat pengaruh positif ethical leadership terhadap job satisfaction.

Berdasarkan hasil penelitian ini, maka beberapa saran yang dapat diberikan oleh peneliti adalah sebagai berikut: Bagi PT BCA, (1) untuk meningkatkan job satisfaction maka perusahaan perlu memperhatikan personality traits karyawan. Kerukunan dan kerjasama antar karyawan sudah cukup baik dan perlu dipertahankan, akan tetapi karyawan masih harus perlu meningkatkan kemampuan pemahaman untuk melihat cara pandang dari sudut orang lain pada personality traits mereka. (2) Variabel lainnya yang penting diperhatikan unytuk meningkatkan job satisfaction adalah ethical leadership, pengambilan keputusan oleh manajer dengan keterbukaan dan keterlibatan karyawan sudah cukup baik dan tetap dipertahankan, akan tetapi dalam penilaian kesuksesan perlu lebih ditingkaktan pada penilaian hasil dan cara mendapatkannya. (3) Faktor dominan yang penting diperhatikan untuk meningkatkan job satisfaction adalah jalur promosi yang adil, sedangkan yang perlu diperbaiki adalah kemampuan karyawan yang cocok dengan pekerjaan. (4) Bagi penelitian selanjutnya diharapkan untuk menambah variabel-variabel lain yang turut mempengaruhi job satisfaction seperti job complexity, job characteristic, job level, dan lain-lain. 
Selain itu, penelitian selanjutnya diharapkan dapat dilakukan dalam satu wilayah penelitian tertentu yang lebih luas, dibandingkan hanya sebatas cabang Kalimalang, Jakarta Timur.

\section{DAFTAR PUSTAKA}

Avey, J. B., Wernsing, T. S., \& Palanski, M. E. (2012). Exploring the process of ethical leadership: The mediating role of employee voice and psychological ownership. Journal of Business Ethics, 107(1), 21-34. doi:http://dx.doi.org/10.1007/s10551-012-1298-2.

Buble, M., (2012), "Interdependence of Organizational Culture and Leadership Styles in Large Firms", Journal of Contemporary Management Issues, 17(2), pp: 85-97.

Borgatta, E. (1964). The structure of personality characteristics. Behavioral Sciences, 9 (1), 8-17.

Chandrasekara, W. S., P. (2019). RELATIONSHIP AMONG BIG FIVE PERSONALITY TRAITS, JOB PERFORMANCE \& JOB SATISFACTION: A CASE OF SCHOOL TEACHERS IN SRI LANKA. International Journal of Information, Business and Management, 11(2), 219-232. Retrieved from https://search.proquest.com/docview/2184341074?accountid=45753.

Cheng-Liang, Y., \& Hwang, M. (2014). Personality traits and simultaneous reciprocal influences between job performance and job satisfaction. Chinese Management Studies, 8(1), 6-26. doi:http://dx.doi.org/10.1108/CMS-09-2011-0079.

Feist, J. \& Gregory J. Feist. (2008). Theories of Personality (Edisi Keenam). Yogyakarta: Pustaka Pelajar.

Feist, J., \& Feist, G. J. (2009). Theories of personality (7th ed.). New York: McGraw Hill.

Greenleaf, R.K. (1977). Servant Leadership: A Journey into the Nature of Legitimate Power and Greatness. Paulist Press, New York.

Guchait, P., Simons, T., \& Pasamehmetoglu, A. (2016). Error recovery performance: the impact of leader behavioral integrity and job satisfaction. Cornell Hosp Q 57:150-161. https://doi.org/10.1177/1938965515613858

Hair, J.F., Sarstedt, M., Ringle, C.M., \& Mena, J.A. (2012), “An assessment of the use of partial least squares structural equation modeling in marketing research", Journal of the Academy of Marketing Science, Vol. 40 No. 3, pp. 414-433.

Haryono, S. (2017). Metode SEM untuk Penelitian Manajemen AMOS LISREL PLS. Jakarta: Luxima Metro Media.

Ko, C., Ma, J., Bartnik, R., Haney, M.H., \& Kang, M. (2018). Ethical leadership: an integrative review and future research agenda. Ethics Behav 28:104-132. https://doi.org/10.1080/10508 422.2017.1318069.

McCrae, R., \& Costa, P. (1985). Updating Norman's “adequate taxonomy": intelligence and personality dimensions in natural language and in questionnaires. Journal of Personality and Social Psychology, 49 (3), 710-721. 
McCrae, R.R. \& Costa, P.T. (1997). Personality trait structure as human universal. American Psychologist, 52, 509-516. Nunnally, J. \& Bernstein, I.H. (1994). Psychometric theory (3rd ed.). New York: McGraw-Hill.

Norman, W. (1963). Toward an adequate taxonomy of personality attributes: replicated factor structure in peer nomination personality ratings. Journal of Abnormal and Social Psychology, 66 (6), 574-583.

Nunnally, J.C. (1967), Psychometric Theory, McGraw-Hill, New York, NY.

Ramadhani, Naila. (2012). Adaptasi bahasa dan Budaya Inventory Big Five. Jurnal Psikologi Vol. 39 No. 2.

Qing, M., Asif, M., Hussain, A., \& Jameel, A. (2019). Exploring the impact of ethical leadership on job satisfaction and organizational commitment in public sector organizations: The mediating role of psychological empowerment. Review of Managerial Science, 1-28. doi:http://dx.doi.org/10.1007/s11846-019-00340-9.

Robbins, S.T. (1996). Perilaku Organisasi, Konsep, Kontroversi dan Aplikasi. Alih Bahasa: Hadyana Pujaatmaka. Edisi Keenam. Penerbit PT.Bhuana Ilmu Populer, Jakarta

Suo, Honggang (2008) A Study On The Relationship Between Personality And Intrinsic Career Success: The Case Of Banking System In Beijing. Masters thesis, USM.

Templer, K. (2012), "Five-factor model of personality and job satisfaction: the importance of agreeableness in a tight and collectivistic Asian society", Applied Psychology, Vol. 61 No. 1, pp. 114-129.

Tokar, D. M., Subich, L. M. (1997) Relative contribution of congruence and personality dimensions to job satisfaction. Journal of Vocational Behavior. 50 (3), pp.482-491.

Tu, Y., Lu, X., \& Yu, Y. (2017). Supervisors' ethical leadership and employee job satisfaction: A social cognitive perspective. Journal of Happiness Studies, 18(1), 229-245. doi:http://dx.doi.org/10.1007/s10902-016-9725-1.

Vijayabanu, C., Amudha, R. (2012) A study on efficacy of employee training: Review of literature. Business: Theory and Practice. 13 (3). pp. 275-282. doi: 10.3846/btp.2012.29. 